Investigating non-technical skills in Scottish and English aircraft maintenance teams using a mixed methodology of interviews and a questionnaire.

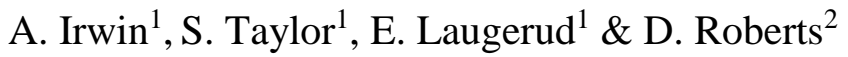 \\ ${ }^{1}$ Industrial Psychology Research Centre, School of Psychology, University of Aberdeen, \\ Aberdeen, UK, AB24 2UB. \\ ${ }^{2}$ Eastern Airways, Aberdeen Airport, Scotland, UK
}

Address for correspondence:

Dr Amy Irwin, School of Psychology, University of Aberdeen, William Guild Building, Aberdeen, AB24 2UB, Scotland, UK.

Tel: (01224) 273003; Fax: (01224) 273211; Electronic mail: a.irwin@abdn.ac.uk 


\begin{abstract}
Background: Aircraft maintenance is a vital aspect of aviation with failures in aircraft maintenance linked to one third of aircraft malfunctions. Research within other high-risk industries indicates the importance of non-technical skills in ensuring effective performance and reducing the risk of error.
\end{abstract}

Objective: The aim of this study was to identify the non-technical skills used by aircraft maintenance crews.

Method: A mixed-methods approach was used: Aircraft maintenance workers from two locations (Scotland and England, $n=24$ ) were interviewed using the critical incident technique. A short survey was then distributed $(n=31)$ to further explore worker perceptions of non-technical skill usage across different organisational locations.

Results: The interviews identified team-based non-technical skills as: Situation awareness, decision-making, leadership, teamwork and communication, and task management. Lone worker non-technical skills were identified as: Situation awareness, decision-making and task management. The questionnaire study indicated that perception of task management was significantly more negative than for situation awareness, leadership, teamwork and communication. Moreover, participants from Scottish units were significantly more positive about situation awareness and teamwork than their English counterparts.

Conclusion: The results indicate that non-technical skills are an important aspect of aircraft maintenance workers' work performance and safety, mirroring the findings reported within other high-risk industries. Variance across organizational units suggests future training programmes must be tailored to fit each team.

Keywords: Non-technical skills; safety; aircraft maintenance; training; lone worker 
In 1985 a Japan Boeing 747 experienced control-system failure during flight, leading to the eventual crash of the aircraft and the loss of many lives. The accident was found to be caused by a maintenance error linked to a rear bulkhead (Civil Aviation Authority, 2002). Analysis of aviation accidents has identified three main categories of causal factors; failure of flight crews to adhere to procedure, aircraft maintenance errors and deficits in the design of aircraft (Reason, 1990). Of those causal factors, failures in aircraft maintenance have been linked to $12 \%$ of accidents and approximately one third of malfunctions (Marx \& Graeber, 1993).

The Civil Aviation Authority (CAA) categorises aircraft maintenance errors as the failure of an aircraft caused by the action, or lack of action on the part of the maintenance team. This can manifest in two ways, the development of an error during maintenance that was not present previously, or the failure to detect an error present in the aircraft when it arrives for maintenance (CAA, 2002). Common error types include omissions, incorrect installations and use of the wrong parts (Graeber \& Marx, 1993). Due to the importance of aircraft maintenance in supporting flight safety and minimising aircraft deterioration, it is vital to identify possible sources of these error types (Endsley \& Robertson, 2000).

Aircraft maintenance usually takes place within a hangar, or on an air field. Work on various aspects of an aircraft is often carried out simultaneously, with the crew working individually or in pairs. Potential adverse environmental factors include working in confined spaces, at height, in darkness, with high levels of noise and in poor weather (Dupont, 1997). Through consideration of these factors Dupont (1997) published the 'dirty dozen', a list of twelve performance-shaping factors that might have an adverse effect on maintenance performance, these include; distraction, lack of knowledge, lack of resources and stress. More recent research reported nine significant risk factors, including; workplace norms (normal practice not based on the appropriate manuals), equipment (equipment shortages, unfinished check-ups) and toxic materials (Chang \& Wang, 2010). 
Research has built on these initial findings to consider the psychosocial aspects of aircraft maintenance. To date findings indicate that factors such as time pressure and lack of training may contribute to maintenance errors (Hobbs \& Williamson, 2002). Fatigue is also a potential factor with crews typically work in a rotating shift pattern to provide maintenance services 24 hours a day, seven days a week (Wang \& Chuang, 2014). Maintenance requires the co-ordination and exchange of information in multiple teams, both across shifts and across different locations (Endsley \& Robertson, 2000). A lack of information, support and feedback across these teams were reported as barriers to maintenance performance (Endsley \& Robertson, 2000). An assessment of safety culture within an aircraft maintenance organisation indicated that production goals can conflict with safety standards, leading to pressure to take shortcuts or tolerate risk (Atak \& Kingma, 2011).

Despite the recognition of multiple factors that may have an adverse impact on maintenance, there is a lack of research examining the skills and techniques required for minimising error and ensuring safe performance. Endsley and Robertson (2000) report that team situation awareness is vital in aircraft maintenance, allowing the successful completion of task goals and minimising errors (Endsley \& Roberston, 2000). Similarly, co-ordination and inter-personal communication have been highlighted as important skills (Suzuki, von Thaden \& Geibel, 2008; Hobbs, 2008). The CAA also lists communication, teamwork and planning as important skills in maintenance activity (CAA, 2003). However, further research is required in order to identify the full set of skills used, create a shared terminology, and design training programmes based around non-technical skills (NTS) specific to aircraft maintenance.

In contrast to aircraft maintenance, there is a large body of research which directly assesses the use of non-technical skills (NTS) within alternative high-risk industries such as healthcare and the oil industry. NTS have been defined as the social (leadership, teamwork 
and communication) and cognitive skills (decision-making, situational awareness, task management) necessary for safe and effective task performance (Flin, O’Connor \& Crichton, 2008). Within industry and healthcare a strong link between NTS and adverse events has been established, for example, adverse events in surgery have been linked to failures in communication and teamwork (Neale, Woloshynowych \& Vincent, 2001). Similarly failures in situation awareness have been linked to offshore drilling incidents (Sneddon, Mearns \& Flin, 2006). Research has focused on identifying NTS across job roles and industries in order to develop skill taxonomies for training and assessment purposes. In order to be reliable training must be developed using specific skills identified as important for a particular job role (see development of ANTS; Fletcher et al., 2004, NOTSS; Yule, Flin, Paterson-Brown \& Maran, 2006). Training programmes based on NTS have been highlighted as a method for improving safety and minimising adverse events within healthcare and industry (Flin \& Patey, 2009; Marquardt, Robelski \& Jenkins, 2011).

Aircraft maintenance represents a high risk industry both in terms of worker safety and the impact of error on aviation accidents. Previous research suggests NTS might be important within this environment, but no formal research exists that has examined the full range of skills within the maintenance setting, despite the large volume of research that focuses on NTS in pilots and flight crew (Flin et al., 2003). Such research is vital as a first step towards the development of a taxonomy of NTS specific to aircraft maintenance workers, and as the baseline for future training programmes in this area.

\section{Study Aim}

The aim of the current study was to identify the non-technical skills required for safe and effective performance of aircraft maintenance staff, both when working alone and as part of a team. 
The primary data source was the analysis of semi-structured interviews with aircraft maintenance engineers and mechanics, based on the critical incident technique. The interview technique allowed the researchers to collect a great amount of detail about the thoughts and actions of maintenance staff during positive and negative incidents. The data were analysed using thematic analysis based on generic NTS categories established within the NTS literature (Mitchell et al., 2011; Fletcher et al., 2004). This analysis allowed the identification of the non-technical skills used and comparison of the reported skills, and behaviours, with those in other high-risk industries such as healthcare (Yule et al.,2006).

In order to enable data triangulation a follow-up study utilising a questionnaire was then conducted. Past research indicates that staff perspective of a particular issue or behaviour (such as teamwork) can function as a determinant of that behaviour (i.e. a positive attitude toward a particular behaviour can increase the incidence of that behaviour; Heinemann, Schmitt, Farrell \& Braillier, 1999). The questionnaire in the current study examined perception of NTS across maintenance workers from multiple units within an aircraft maintenance organisation. The aim was to confirm the NTS identified in the interviews and to gain an indication of the utilisation of each skill across different maintenance units.

\section{Qualitative interviews to assess the use of NTS by aircraft maintenance workers}

\section{Method}

\section{Design}

The critical incident technique (Flanagan, 1954; Butterfield, Borgen, Amundsen \& Maglio, 2005) formed the basis for each semi-structured interview. During the interview participants were asked to verbally recall two past incidents (one negative and one positive): Positive incidents were categorised as incidents with a positive outcome, where there were no errors 
or adverse consequences associated with actions. Negative incidents encompassed any event which resulted in an error, accident or injury. The interviewer then asked further questions to discover the tacit knowledge and skills used (Sternberg \& Horvath, 1999; Mitchell et al., 2011). When developing the interview questions generic NTS identified for safety critical jobs (Flin et al., 2008) were considered. This was in order to examine those skill categories, while still retaining enough flexibility for other skills to be identified.

\section{Ethical approval}

This study was approved by the University of Aberdeen, School of Psychology ethics committee, Scotland (June 2015).

\section{Participants}

A total of 24 participants (all male, age range 18 - 61 years, mean age: 40.2 ) were recruited within a three month period. Participants were recruited from within a single aircraft maintenance organisation, and two geographical regions (Scotland $n=16$ and England $n=$

8). All of the participants worked full time within aircraft maintenance, with a reported range of experience from two weeks $(n=1$; this participant had 5 years experience in aircraft maintenance, but had only recently joined the current organisation) to 10 years within the current aircraft maintenance organisation. The majority of the participants $(n=20)$ were licenced engineers, the remainder $(n=4)$ were aircraft mechanics. Participants were sent the invitation e-mail and information sheet by a central organisation contact, that contact also arranged interview dates and times for all participants based on work shift schedules.

\section{Data collection}

Digitally recorded interviews lasting between 30 and 50 minutes were conducted between June and August 2015 (by second author ST). The interviews were all conducted at the 
participants' place of work, within a quiet room on the premises. All interview recordings were transcribed verbatim by one researcher (ST).

As part of the critical incident technique (Flanagan, 1954), participants were asked to recount one adverse incident, which had resulted in an accident or injury, and one positive maintenance example, which had resulted in a good outcome. The interviewees were asked to describe the incidents in detail, and were given time to discuss their thoughts and feelings, along with their own actions and the actions of any others present.

In the second section of the interview, participants were asked further questions about their behaviours while working as part of a team, and when working alone, using questions adapted from previous research on non-technical skills (see Mitchell et al., 2011; Irwin \& Poots, 2015 for full details).

Data saturation, the point at which no new concepts or behaviours are being identified within the interview transcripts, was determined according to the suggested principles outlined by Francis et al. (2010). First the initial sample size was set at 12 interviews (Guest, Bunce \& Johnstone, 2006). Second, a stopping criterion for data collection was set at 2 consecutive interviews where no new concepts or behaviours were identified.

In practice this meant that an initial sample $(n=12)$ was gathered from the Scottish office of the maintenance organisation, 4 further interviews were conducted (two sets of two consecutive interviews). Within the final two interviews no new concepts or behaviours were identified and so data saturation was determined to have been reached after 16 interviews. In order to ensure the reliability and generalisability of the results, a further 8 interviews were then conducted at the English office of the organisation, where protocol and usual procedures differed slightly from the Scottish office (the English crews were primarily hangar based, whereas the Scottish crews worked across multiple locations and environments). No new 
concepts or behaviours were found within the additional interviews, as such the data from both locations was combined and all references to the data from this point can be assumed to include both the English and the Scottish data.

\section{Data analysis}

The interview transcripts were analysed using thematic analysis (Braun \& Clarke, 2006) by the first and second authors. All coding and analysis were conducted using the qualitative analysis software Nvivo 10.

The main non-technical skill categories found in other safety critical job roles (Mitchell et al., 2011; Flin et al., 2008) were used as the basis of the initial coding system. The first five transcripts were read and coded using these categories by the first author (AI), with the coding system altered iteratively as behaviours specific to the aircraft maintenance environment were identified.

Once data collection had ceased, the first author (AI) re-read all of the manuscripts, and checked the coding strategy used for consistency. The second author (ST) then read and coded 10 transcripts in order to allow inter-rater reliability to be calculated using Nvivo 10. The results indicated a good level of agreement between the raters $(k=0.8)$ for the main nontechnical skill categories.

Finally, the non-technical skills generated by this research were examined by a subject matter expert from within the aircraft maintenance organisation to ensure they matched with reasonable expectations of skills within this area.

\section{Results}

The analysis of the interview transcripts produced themes within three main areas: Factors leading to errors or accidents, team NTS and lone worker NTS. 


\section{Factors leading to errors or accidents}

The participants were asked to recall the number of accidents and injuries they had suffered while at work over the past five years. Only three of the participants reported an injury that required hospitalisation; an eye injury, a back injury and a broken ankle. The majority $(n=$ 21) stated that they had not experienced what they considered to be a 'serious' injury. The entire sample reported numerous frequent 'non-serious' injuries, included cuts, bruising, metal splinters, mild eye injuries and minor bumps to the head.

The participants were also asked to report the main factors that might lead to an accident or error within aircraft maintenance (Table 1). The primary causes of concern were commercial pressure (e.g. pressure to sign off on a maintenance task quickly to avoid costly delays), working while tired and the difficulties inherent to working in a cramped, cold and sometimes dark environment. When discussing these factors participants referred to dangers to self, or flight safety, or both. Table 1 illustrates the primary focus of concern for each reported factor.

Table 1: Number of participants reporting adverse factors in aircraft maintenance working environment with reference to dangers of injury to self, or risk to flight safety.

\begin{tabular}{|l|c|c|c|}
\hline Aircraft Maintenance Factor & $\begin{array}{l}\text { Number of } \\
\text { participants } \\
\text { reporting factor }\end{array}$ & Risk to self & $\begin{array}{l}\text { Risk to flight } \\
\text { safety }\end{array}$ \\
\hline Commercial pressure & 17 & $\mathrm{X}$ & $\mathrm{X}$ \\
\hline Tiredness & 13 & $\mathrm{X}$ & $\mathrm{X}$ \\
\hline $\begin{array}{l}\text { Physical work environment } \\
\text { (cold, dark, confined, loud) }\end{array}$ & 7 & & $\mathrm{X}$ \\
\hline $\begin{array}{l}\text { Lack of resources (parts, out of } \\
\text { date manuals) }\end{array}$ & 5 & $\mathrm{X}$ & $\mathrm{X}$ \\
\hline Lack of experience or training & 3 & & $\mathrm{X}$ \\
\hline Repetitive tasks & 3 & $\mathrm{X}$ & \\
\hline Adverse weather (rain, snow & 3 & & \\
\hline
\end{tabular}




\begin{tabular}{|l|c|c|c|}
\hline etc.) & & & \\
\hline Failure to follow protocol & 3 & $\mathrm{X}$ \\
\hline Heavy lifting & 3 & $\mathrm{X}$ & \\
\hline Hazardous chemicals & 2 & $\mathrm{X}$ & $\mathrm{X}$ \\
\hline $\begin{array}{l}\text { Lack of required number of } \\
\text { staff }\end{array}$ & 2 & $\mathrm{X}$ & \\
\hline Working at height & 2 & & \\
\hline
\end{tabular}

\section{Non-technical skills}

Thematic analysis identified both team-based and individual NTS, as summarised by Table 2

below. This confirmed the relevance of NTS in aircraft maintenance.

Table 2: Summary of main NTS categories for team and lone worker.

\begin{tabular}{|l|l|}
\hline \multicolumn{2}{|c|}{ Non-Technical Skills } \\
\hline Team-based & Lone worker \\
\hline $\begin{array}{l}\text { Situation awareness } \\
\text { Shared awareness and understanding of } \\
\text { environment and work task. Includes } \\
\text { location and behaviours of team-mates. }\end{array}$ & $\begin{array}{l}\text { Situation awareness: } \\
\text { Individual awareness and understanding of } \\
\text { environment and work task. }\end{array}$ \\
\hline $\begin{array}{l}\text { Decision-making: } \\
\text { Team-based decision-making based on } \\
\text { shared information. }\end{array}$ & $\begin{array}{l}\text { Decision-making: } \\
\text { Lone worker decision-making made in } \\
\text { isolation (unless decision is made to involve } \\
\text { another worker). }\end{array}$ \\
\hline $\begin{array}{l}\text { Task management: } \\
\text { Shared task management, including an } \\
\text { awareness of actions taken by other } \\
\text { members of the team. }\end{array}$ & $\begin{array}{l}\text { Task management: } \\
\text { Individual task management based on task }\end{array}$ \\
\hline $\begin{array}{l}\text { Teamwork and communication: } \\
\text { Inter-relationships and information sharing } \\
\text { across the team. }\end{array}$ & \\
\hline $\begin{array}{l}\text { Leadership: } \\
\text { Directing and supporting behaviours by } \\
\text { team leader. }\end{array}$ & \\
\hline
\end{tabular}

The workers discussed these skills primarily in reference to maintaining aircraft safety and flight worthiness. However, it is worth noting that team-based situation awareness included consideration of the movements of other workers in order to avoid physical injury through movement of equipment. In addition, the majority of the participants identified risk of injury 
to self as one of the main concerns when working alone. As a consequence many of the loneworker NTS included consideration of dangers to self, as well as to flight safety.

\section{Team non-technical skills}

All of the participants reported that they worked as part of a team, but that certain aspects of aircraft maintenance sometimes necessitated working alone. The skills identified when working as part of a team are illustrated in Table 3.

Table 3: Thematic analysis of reported aircraft maintenance worker (AMW) behaviour when working as part of a team, organised into five distinct non-technical skills categories.

\begin{tabular}{|c|c|c|c|}
\hline $\begin{array}{l}\text { Non-technical skill } \\
\text { category }\end{array}$ & Coded skill & $\begin{array}{l}\text { Number of } \\
\text { participants } \\
\text { reporting } \\
\text { skill }\end{array}$ & $\begin{array}{l}\text { Quotation with participant number } \\
(\mathrm{P}-)\end{array}$ \\
\hline \multirow[t]{3}{*}{$\begin{array}{l}\text { Situation } \\
\text { Awareness }\end{array}$} & $\begin{array}{l}\text { Perception of } \\
\text { surroundings }\end{array}$ & 19 & $\begin{array}{l}\text { 'You have to watch where you are } \\
\text { going, what is in-front of you and } \\
\text { what is behind you' P6 }\end{array}$ \\
\hline & $\begin{array}{l}\text { Comprehension of } \\
\text { situation (including } \\
\text { impact of actions on } \\
\text { flight safety) }\end{array}$ & 19 & $\begin{array}{l}\text { 'There was a component getting } \\
\text { power that shouldn't have been' P3 }\end{array}$ \\
\hline & $\begin{array}{l}\text { Prediction of future } \\
\text { events }\end{array}$ & 18 & $\begin{array}{l}\text { 'If you have taken something out and } \\
\text { left it out the possibility is that the } \\
\text { cables move and chafe and you can } \\
\text { have failures in other systems' P15 }\end{array}$ \\
\hline \multirow[t]{3}{*}{ Decision-making } & $\begin{array}{l}\text { Assessment and } \\
\text { management of risk }\end{array}$ & 17 & $\begin{array}{l}\text { 'We stopped the task we were } \\
\text { proceeding with because we didn't } \\
\text { want to damage the aircraft any } \\
\text { further' P15 }\end{array}$ \\
\hline & $\begin{array}{l}\text { Assessment of flight } \\
\text { safety }\end{array}$ & 14 & $\begin{array}{l}\text { 'The most important thing is whether } \\
\text { the aircraft can be flown or not in } \\
\text { accordance with the manuals' } P 1\end{array}$ \\
\hline & $\begin{array}{l}\text { Assessment of } \\
\text { alternative strategies } \\
\text { (dealing with complex }\end{array}$ & 12 & $\begin{array}{l}\text { 'Took the time to sit down and find } \\
\text { out exactly what was going on...then } \\
\text { over the course of two days resolve }\end{array}$ \\
\hline
\end{tabular}




\begin{tabular}{|c|c|c|c|}
\hline & problems) & & the issue'P8 \\
\hline & $\begin{array}{l}\text { Balancing conflicting } \\
\text { demands }\end{array}$ & 8 & $\begin{array}{l}\text { 'You have one of two paths to take, } \\
\text { you either follow the procedure for } \\
\text { making it safe or you follow the } \\
\text { procedure for fixing it'P15 }\end{array}$ \\
\hline \multirow[t]{5}{*}{ Leadership } & $\begin{array}{l}\text { Directing and co- } \\
\text { ordinating task } \\
\text { behaviours }\end{array}$ & 17 & $\begin{array}{l}\text { 'Planning and deciding what part of } \\
\text { the work pack gets done by whom' } \\
\text { P12 }\end{array}$ \\
\hline & $\begin{array}{l}\text { Monitoring staff and } \\
\text { overall task } \\
\text { progression }\end{array}$ & 15 & $\begin{array}{l}\text { 'I will go down and see how things } \\
\text { are progressing'P3 }\end{array}$ \\
\hline & Supporting staff & 11 & $\begin{array}{l}\text { 'I make sure the guys have } \\
\text { everything they need, I keep up their } \\
\text { well-being' } P 2\end{array}$ \\
\hline & Organising contacts & 7 & $\begin{array}{l}\text { 'Any form of contact externally, } \\
\text { asking when a job will arise, should } \\
\text { always come through him } \\
\text { [supervisor]'P8 }\end{array}$ \\
\hline & Enabling change & 6 & $\begin{array}{l}\text { 'We discovered the situation and } \\
\text { said from this day on this type of job } \\
\text { will not be done again' } P 1\end{array}$ \\
\hline \multirow[t]{5}{*}{$\begin{array}{l}\text { Teamwork \& } \\
\text { Communication }\end{array}$} & $\begin{array}{l}\text { Sharing information } \\
\text { within the team }\end{array}$ & 20 & $\begin{array}{l}\text { 'We are always phoning each other } \\
\text { and talking about what we are doing } \\
\text { on the job' } P 4\end{array}$ \\
\hline & Sharing workload & 13 & $\begin{array}{l}\text { 'If anyone reaches the end of their } \\
\text { task and someone else has something } \\
\text { needing to be done, quite often they } \\
\text { will go and visit the guy who is } \\
\text { working and ask if they need a hand' } \\
\text { P8 }\end{array}$ \\
\hline & $\begin{array}{l}\text { Reporting task } \\
\text { progress }\end{array}$ & 12 & $\begin{array}{l}\text { 'We keep head office updated... if } \\
\text { they want the aircraft in half an hour } \\
\text { you have to tell them when it will be } \\
\text { ready' P3 }\end{array}$ \\
\hline & Co-ordination & 10 & $\begin{array}{l}\text { 'If you are down the line and you } \\
\text { need a part...somebody else can go } \\
\text { and get the part and you are free to } \\
\text { keep doing the job'P3 }\end{array}$ \\
\hline & Authority and & 8 & $\begin{array}{l}\text { 'I said to him that all needs } \\
\text { replacing, he said no it doesn't, I }\end{array}$ \\
\hline
\end{tabular}




\begin{tabular}{|c|c|c|c|}
\hline & assertiveness & & $\begin{array}{l}\text { said yes it does because it is burnt } \\
\text { out' P11 }\end{array}$ \\
\hline & $\begin{array}{l}\text { Checking the work of } \\
\text { others }\end{array}$ & 7 & $\begin{array}{l}\text { 'There is an engineer with me and he } \\
\text { can say they [the parts] are fine' P13 }\end{array}$ \\
\hline & $\begin{array}{l}\text { Exchanging } \\
\text { information at shift } \\
\text { handover }\end{array}$ & 7 & $\begin{array}{l}\text { 'You need clarity when you are } \\
\text { handing over something, rather than } \\
\text { just saying you need to put it back } \\
\text { together'P15 }\end{array}$ \\
\hline \multirow[t]{4}{*}{ Task management } & Time management & 18 & $\begin{array}{l}\text { 'You know how long the job is going } \\
\text { to take and you need to have the } \\
\text { aeroplane ready for the next } \\
\text { morning' P12 }\end{array}$ \\
\hline & $\begin{array}{l}\text { Maintaining standards } \\
\text { / following protocol }\end{array}$ & 17 & $\begin{array}{l}\text { 'We also work with procedures and } \\
\text { go through it step by step to try and } \\
\text { minimise errors' P1 }\end{array}$ \\
\hline & Preparation & 14 & $\begin{array}{l}\text { 'You have to assess the job, assess } \\
\text { what you have got, what you will } \\
\text { need, and then put it all in place' } \\
\text { P15 }\end{array}$ \\
\hline & $\begin{array}{l}\text { Organization of } \\
\text { resources (parts, } \\
\text { equipment etc.) }\end{array}$ & 9 & $\begin{array}{l}\text { 'You need to be able to get your } \\
\text { hands on the parts you need' P13 }\end{array}$ \\
\hline
\end{tabular}

\section{Situation awareness}

Awareness of people and equipment within the environment, combined with recognition of cues that allowed prediction of the consequences of action were highlighted by interviewees as important skills. This was particularly evident in the description of adverse incidents, where failures in situation awareness were reported across the majority of incidents $(n=19)$. This lack of awareness was often linked to a general lack of attention, or complacency $(n=$ 7):

'We didn't check, we just assumed because no-one told us there had been anyone near [the aircraft]' $P 9$ 
Interviewees were also aware of the potential impact of their actions on flight safety. Several participants $(n=6)$ reported thinking about the safety of aircraft passengers while carrying out maintenance work.

\section{Decision-making}

One of the most frequently reported aspects of decision-making was the assessment of an aircraft in terms of whether it would be fit to fly. This encompassed a certain level of risk tolerance, whereby a decision had to be made in each case as to whether the aircraft could continue to fly if a particular problem or issue was not fixed in the time allowed. These decisions were made in the context of expert knowledge regarding system redundancies built into every aircraft, whereby aircraft can function safely should something fail. Items of equipment that can be unserviceable during flight are set out by the Master Minimum Equipment List (MMEL) provided by the CAA. The ideal from a maintenance perspective is to have every item of equipment in working order, but the participants reported that this was not always possible due to constraints:

'It allows the aircraft companies to fly with certain bits not working. You have to make the decision do I need to fix this straight away, do I have time to fix this straight away, is the aircraft required to fly straight away'. P15

Many of the participants considered dealing with complex problems to be an important aspect of their work $(n=12)$, this encompassed the identification of problems, diagnosis and the production of a plan of action.

\section{Leadership}

Interviewees considered one of the main functions of a leader to be the coordination of the maintenance crew. This included the assessment of team members according to their 
strengths and weaknesses, in order to allocate them an appropriate role or task. This also required maintaining an oversight of the workflow across a shift, in order to prioritise tasks or reallocate team members according to requirements:

'If a big job comes up he [the supervisor] will shuffle the shift and say can you come off that job and go and give so and so a hand.' $P 9$

In addition to this, leaders were reported as making changes to protocol and procedures in response to incidents or events within the working environment.

\section{Teamwork and communication}

The primary aspect of teamwork reported was sharing workload. In order to share workload participants reported that if a worker was experiencing a problem the others would 'bounce ideas around' in order to help their teammate come to a resolution. In addition, team members assessed the needs of others once they completed their own element of the task, in order to offer help where it is needed:

'If somebody reaches the end of their task and someone else has something needing doing they will quite often go and visit the guy who is working and ask if they need a hand.' P8 Another important aspect of teamwork and communication was the ability to utilize authority, or assertiveness when required. This was usually reported in conjunction with erroneous requests, or additional pressure from management:

'Everybody wants you to start but at certain times you have got to say no I am not doing it'. 


\section{Task management}

Time management was an important skill within task management. Appropriate time management required the prioritization of tasks according to deadline, a calculation of the time required for each job and the management of multiple tasks. When time management failed interviewees reported feeling rushed, or stressed, and indicated that the risk of error increased. When time was managed successfully this could lead to feelings of satisfaction, particularly when a job was completed 'ahead of time'.

\section{Lone-worker non-technical skills}

The majority $(n=18)$ of the maintenance staff reported that they worked alone, out of sight of others, more than once a week. All of the interviewees who worked alone reported that the main hazard was the risk of injury when no one was around to help:

\section{'If you knock yourself out no one will be there to rescue you.' P12}

Several participants $(n=5)$ also felt that working alone may compromise the accuracy or quality of the work, due to the lack of a second opinion from team-mates, or the risk of fatigue impacting the conducted work. When discussing working alone, the participants reported a sub-set of the NTS identified for working as part of a group, as illustrated in Table 4.

Table 4: Thematic analysis of reported aircraft maintenance worker (AMW) behaviour when working alone; organised into three non-technical skills categories.

\begin{tabular}{|l|l|l|l|}
\hline $\begin{array}{l}\text { Non-technical skill } \\
\text { category }\end{array}$ & Coded skill & $\begin{array}{l}\text { Number of AMW's } \\
\text { reporting skill }\end{array}$ & Example \\
\hline Situation awareness & $\begin{array}{l}\text { Awareness and } \\
\text { understanding of } \\
\text { environment }\end{array}$ & 14 & $\begin{array}{l}\text { 'Be aware of your } \\
\text { situation, what you } \\
\text { have to do and your } \\
\text { surrounding } \\
\text { environment.' } P 2\end{array}$ \\
\hline
\end{tabular}




\begin{tabular}{|c|c|c|c|}
\hline & $\begin{array}{l}\text { Anticipation of future } \\
\text { events }\end{array}$ & 5 & $\begin{array}{l}\text { 'You will generally } \\
\text { know with a bit of } \\
\text { experience going to a } \\
\text { job historically } \\
\text { whether they are } \\
\text { going to be a } \\
\text { problem or not.' P8 }\end{array}$ \\
\hline \multirow[t]{2}{*}{ Decision-making } & Flight safety & 13 & $\begin{array}{l}\text { 'If the aircraft is air } \\
\text { worthy.' } P 7\end{array}$ \\
\hline & $\begin{array}{l}\text { Assessment and } \\
\text { management of risk }\end{array}$ & 18 & $\begin{array}{l}\text { 'If you are starting to } \\
\text { dismantle things and } \\
\text { take bits off on your } \\
\text { own you have to } \\
\text { think about that.' P6 }\end{array}$ \\
\hline Task Management & $\begin{array}{l}\text { Maintaining } \\
\text { standards / following } \\
\text { protocol }\end{array}$ & 12 & $\begin{array}{l}\text { 'Self-monitoring; } \\
\text { making sure you are } \\
\text { doing the job } \\
\text { correctly and follow } \\
\text { the relevant } \\
\text { procedures.' P8 }\end{array}$ \\
\hline
\end{tabular}

The skills reported when working alone differed from team NTS in several ways. First, when discussing situation awareness workers reported awareness based on the structures around them, and the nature of the task. They did not include other workers in this assessment. Second, the assessment and management of risk was primarily focused on assessment of potential risk to the worker based on the prescribed task, rather than consideration of risk to others. Finally, many of the workers reported that maintaining standards was a way of monitoring their own work. By double checking their work, and adhering to the maintenance manuals, they felt they could ensure their effectiveness and work quality. 


\section{Survey of aircraft maintenance personnel perception of NTS}

\section{Method}

\section{Questionnaire}

The questionnaire was based on an adaptation of the TeamSTEPPS Teamwork Perceptions Questionnaire (T-TAQ; Baker, Krokos \& Amodeo, 2008) with items altered to refer explicitly to aircraft maintenance. The questionnaire featured six self-report subscales designed to assess individual perception of group-based behaviours linked to the NTS identified in the interview study. Items were designed to assess perception of NTS performance, e.g. 'Team members share relevant information with each other regarding potential complications.' Within each section two original questions were added based on the information extracted from the interviews. In each case the added elements were not covered in the original T-TAQ. Each question was answered using a five-point Likert scale, ranging from five: 'strongly agree' to one: 'strongly disagree.' Each sub-scale featured 8 items, of which two were phrased negatively e.g. ' my team fails to make efficient use of available resources.' These items were reverse coded before being included in the scale score for each sub-scale ( $25 \%$ items reverse coded). The six sub-scales included in the questionnaire were: situation awareness, teamwork, leadership, task management, decisionmaking and communication.

\section{Ethical approval}

This study was approved by the University of Aberdeen, School of Psychology ethics committee, Scotland (approved October 2015). 


\section{Participants}

Aircraft maintenance staff were recruited from within the same maintenance organization as described for the interview study. This encompassed six geographically distinct units within three countries (England $n=18$; Scotland $n=12$; Germany $n=1$ ). A total of 31 participants, one female, with an age range of 24 to 66 years (entire sample mean: 44.5 years; Scotland: 42.8 years; England: 46.1 years), completed the questionnaire ( $44 \%$ response rate). The majority of the participants were licensed maintenance engineers $(n=25)$, with four mechanics, and two individuals primarily based within documentation control. All participants reported a minimum of one year of experience within their current organization, and location (mean experience: Scotland: 19.3years, England: 12.7years).

\section{Data collection}

Recruitment was conducted using an e-mail invitation letter sent to the manager of each unit within the maintenance company (there were six units in total, with staff numbers within each unit ranging from 2 to 28 ). The manager of each unit then distributed the e-mail invitation to their maintenance staff.

The questionnaires were anonymous, participants completed an electronic consent sheet, and then the questionnaire online, with data collection occurring via SNAP, an online questionnaire management programme.

\section{Data analysis}

A total score was calculated for each of the six questionnaire subscales (situation awareness, teamwork, leadership, decision-making, task management and communication). The score could range from a minimum of 8 , to a maximum of 40 ( 8 items per subscale). A score of 8 would indicate a negative perception of NTS, a score of 24 indicates a predominantly neutral 
response and a score of 40 would indicate a positive perception of NTS. Scale reliability analysis was carried out, followed by correlation, a mixed measures ANOVA; non-technical skills represents the within-subject factor (with five levels denoted by five subscales) and geographical location (country) was the between-subjects factor (due to lack of numbers, only Scotland and England are included as geographical locations, Germany was excluded from the analysis). Finally, a one-way ANOVA was conducted to assess each of the NTS constructs across geographical location.

\section{Results}

In order to ensure each subscale had an acceptable level of internal consistency, a scale reliability analysis was conducted using Cronbach's alpha $(\alpha)$. As illustrated by Table 5 below all of the subscales, with the exception of decision-making, exhibited an acceptable to good level of internal consistency (George \& Mallery, 2003). The subscale of decisionmaking showed a 'poor' level of internal consistency, which could not be increased through item removal, suggesting the scale does not reliably assess the construct decision-making in the environment of aircraft maintenance, and as such was removed from further analysis.

Table 5: Scale reliability analysis using Cronbach's Alpha ( $\alpha$ ), for each of the six constructs within the T-TAQ adaptation questionnaire.

\begin{tabular}{|l|l|l|}
\hline Subscale construct & Number of items & $\boldsymbol{\alpha}$ \\
\hline Situation awareness & 8 & 0.78 \\
\hline Decision-making & 8 & 0.37 \\
\hline Leadership & 8 & 0.85 \\
\hline Teamwork & 8 & 0.73 \\
\hline Communication & 8 & 0.87 \\
\hline Task management & 8 & 0.70 \\
\hline
\end{tabular}

Following assessment of subscale reliability correlation analysis was used to assess associations between the NTS constructs. Table 6 indicates that the correlation coefficients 
ranged from .39 (leadership and task management) to .72 (situation awareness and leadership). Leadership and communication were not significantly correlated, but the remainder of the constructs were significantly correlated.

Table 6: Correlations for NTS constructs (situation awareness, leadership, teamwork, communication, task management).

\begin{tabular}{|l|l|l|l|l|l|}
\hline NTS & 1 & 2 & 3 & 4 & 5 \\
\hline 1. Situation awareness & 1 & & & & \\
\hline 2. Leadership & $.716^{* *}$ & 1 & & & \\
\hline 3. Teamwork & $.635^{* *}$ & $.650^{* *}$ & 1 & & \\
\hline 4. Communication & $.385^{*}$ & .311 & $.601^{* *}$ & 1 & \\
\hline 5. Task management & $.472^{*}$ & $.390^{*}$ & $.474^{* *}$ & $.558^{* *}$ & 1 \\
\hline
\end{tabular}

** Correlation significant at the 0.01 level. * Correlation significant at the 0.05 level.

In order to determine whether the mean reported perception of NTS (a high score indicates a high level of agreement with the utilisation of a NTS by the team) varied across subscales and geographical location, a mixed-measures ANOVA was conducted (5 NTS x 2 geographical location. The single German participant was excluded from the analysis). The results indicated there was a significant difference in perception across the five NTS subscales $(\mathrm{F}(4$, $\left.100)=20.18, p=.001, \eta_{\mathrm{p}}^{2}: .45\right)$, there was no significant interaction $(\mathrm{F}(4,100)=1.04, p=$ .39). There was also a significant difference in perception of NTS across geographical location $\left(\mathrm{F}(1,25)=7.28, p=.012, \eta_{\mathrm{p}}^{2}=.23\right)$. This finding indicates that perception of the different subscales varied (see Table 7). Post-hoc comparisons using the Bonferroni correction indicated that perception of situation awareness, leadership, teamwork and communication did not differ significantly from one another $(p>.05)$, but were all significantly different (more positive) than perception of task management $(p<.05)$.

In order to explore the difference across geographical location further, a one-way ANOVA was conducted to assess differences across each subscale (see Table 7). The results indicate that perception of situation awareness and teamwork were significantly more 
positive in Scottish units compared to English units. There was no significant difference in perception of communication, leadership and task management.

Table 7: Mean values for perception of NTS, compared across geographical location using ANOVA analysis.

\begin{tabular}{|l|l|l|l|}
\hline Construct & Geographical location & Mean & ANOVA \\
\hline \multirow{2}{*}{ Situation awareness } & Scotland & $\mathbf{3 4 . 0 8}$ & $\mathbf{F}(\mathbf{1}, \mathbf{2 9})=\mathbf{7 . 7 4}$, \\
& England & $\mathbf{. 0 1 0}$ \\
\hline \multirow{2}{*}{ Leadership } & Scotland & $\mathbf{3 0 . 1 7}$ & $\mathrm{F}(1,27)=3.88$, \\
& England & 33.30 & $p .060$ \\
\hline \multirow{2}{*}{ Teamwork } & Scotland & 28.89 & $\mathbf{F}(\mathbf{1}, \mathbf{2 8})=\mathbf{1 8 . 7 6}$, \\
& England & $\mathbf{3 4 . 7 2}$ & $\mathbf{p}=01$ \\
\hline \multirow{2}{*}{ Communication } & Scotland & $\mathbf{2 9 . 1 1}$ & $\mathrm{F}(1,27)=3.15, p$ \\
\cline { 2 - 3 } & England & 31.55 & $=.088$ \\
\hline \multirow{2}{*}{ Task management } & Scotland & 28.17 & $\mathrm{~F}(1,28)=1.24, p$ \\
& England & 25.81 & $=.275$ \\
\hline
\end{tabular}

\section{Discussion}

The results of the current study build upon and extend previous research findings on the importance of NTS within high-risk industries (Flin et al., 2003) to an application in aircraft maintenance. Based on the incidents described in the interview study, it was apparent that NTS were utilized by aircraft maintenance workers, both when alone and when working as a team. Failures in these skills were reported as potential causal factors in adverse events or errors. Workers were concerned primarily with errors influencing flight safety, with errors leading to personal injury a secondary concern. The majority of these skills appear to develop through experience, because no training based on NTS was reported as currently in use within aircraft maintenance. Finally, the questionnaire data indicated that perception of NTS was reasonably positive, but variance across geographical location, with Scottish workers generally reporting higher levels of performance, suggests that future training programmes should be tailored to each team or base of operations. 
These findings provide the basis for a common terminology to discuss NTS within maintenance companies, and as such could function as a baseline for the development of future training and assessment programmes. Previous programmes within aircraft maintenance have focused solely on one skill (situation awareness: Endsley \& Robertson, 2000, teamwork; Kraus \& Gramopadhye, 2001) and do not, therefore, encompass the full variety of skills indicated here as required for safe and efficient maintenance practice. Certainly research within other high-risk industries has sought to develop NTS taxonomies that encompass the full range of skills. On this basis NTS training has already been implemented in medical undergraduate training (Flin \& Patey, 2009), commercial aviation (Flin et al., 2003) and healthcare (Fletcher et al., 2004).

\section{Limitations}

However, though the results of the current study can be generalised to a certain extent, due to two countries being included across both studies, it was recognised that all participants were drawn from within a single organization. As such further research with workers from additional aircraft maintenance organizations and countries is required to determine the application of these findings in areas other than the UK and Europe. It should also be noted that the results reported in the interview study were based on self report and may be vulnerable to individual bias or the inaccuracy of memory. Furthermore, the sample was almost wholly male, and as such any impact of gender on attitudes towards NTS cannot be examined here.

The questionnaire study was also limited by sample size, whereby there were not sufficient participants to conduct a confirmatory or exploratory factor analysis to confirm the six factor model set out for the T-TAQ (Comrey \& Lee, 1992). There may also be an element of acquiescent responding, a tendency to respond with agreement (Rammstedt, 
Danner \& Bosnjak, 2017), due to the relatively restricted (25\%) level of reverse coded items. This bias may partially explain the generally positive response to the NTS categories. Finally, this paper represents an exploratory study to assess the application of NTS within aircraft maintenance. Having established that NTS are relevant within this area, further research is now required to use the information gathered here to develop a behavioural marker system.

\section{Adverse factors}

The primary factors reported in the current study as having a potentially adverse impact on maintenance performance were commercial pressure, fatigue and the physical environment. All three factors have also been reported within commercial aviation as causal factors in accidents (Shappell et al., 2007). Commercial pressure in particular has been linked with a variety of adverse effects including reduced incident reporting, poor fatigue management, reduced staff numbers in aviation (Darbra, Crawford, Haley \& Morrison, 2007) and pressure, to 'sign-off' on maintenance tasks before they are ready (Chang \& Wang, 2010; Hampson, Junor \& Gregson, 2012). Fatigue has been shown to be associated with low levels of situation awareness (Sneddon, Mearns \& Flin, 2006), which due to the importance of the skill in the current study represents an important risk factor for NTS performance. Further research is needed to assess the potential links between reported adverse factors and NTS performance across a range of disciplines.

\section{Team non-technical skills}

The current research indicates that perception of team-based NTS can vary across different units within an organization. In this case Scottish maintenance staff reported a higher level of NTS performance than English workers for situation awareness and teamwork. This may be due to cultural variation or contextual factors, certainly past research has indicated that the 
response to NTS-based training can differ according to organizational or national culture (Helmreich, Merritt \& Wilhelm, 1999). There is also evidence to suggest that acquiescence may vary on a country by country basis (Rammstedt et al., 2017), in this case possibly Scottish participants were more subject to acquiescence than English participants. Moreover, within healthcare attitudes towards safety climate have been found to differ across hospital, discipline and work area (Singer et al., 2009). Perception of teamwork and communication has also been shown to vary across job role (Sexton, Thomas \& Helmreich, 2000). Further research is needed in order to examine factors which may influence NTS, as this kind of variance may influence the effectiveness of training programmes (Helmreich et al., 1999).

One of the two factors which differed significantly according to location was situation awareness. The current results support Endsley and Robertson's (2000) suggestion that team situation awareness is integral to aircraft maintenance, and that barriers, such as the lack of appropriate tools or equipment, can have an adverse impact on task performance. Endsley (2015) also emphasised the role of expectations in guiding attention as an important element in situation awareness. The current interview data emphasises the importance of assumptions, or pre-conceptions on situation awareness in aircraft maintenance. In adverse incidents false assumptions were reported to lead to error, or delay, due to faulty information.

The accurate perception and comprehension of environmental information is linked to the process of decision-making and task-based actions (Endsley, 2015). The current interview data suggest that decision-making is an important aspect of aircraft maintenance, particularly when a decision must be made as to whether the aircraft is safe to fly. The nature of the decisions encapsulated by this construct may differ from decision-making constructs stated elsewhere, certainly responses to questions based on decision-making from the T-TAQ varied widely, possibly the cause for the unreliable estimate of scale consistency from the questionnaire data. The categorization of decisions made within maintenance could be a 
focus of future research, certainly the importance of maintenance decisions relevant to flight safety has previously been highlighted in adverse incident analyses, with failures linked to potentially catastrophic maintenance errors (AAIB, 1996).

When describing adverse incidents aircraft maintenance workers reported that it was sometimes necessary for them to express safety concerns. The interview data highlighted the need to speak assertively as an important element of teamwork and communication. Speaking out about safety issues in aircraft maintenance has previously been discussed as part of organizational safety culture and reported to be associated with positive safety outcomes (Taylor \& Thomas, 2003). Research within a range of industries, including maintenance and commercial aviation, suggests that barriers to speaking up, such as fear of retribution, or lack of support from supervisors, can lead to errors or adverse events occurring (Taylor \& Thomas, 2003).

Task management was identified as an important skill by the majority of interviewees in the current study, yet attitudes towards task management were significantly more negative than towards the remaining NTS. This negative attitude may be linked to reports of manuals and protocols that were not fit for purpose within the interview data. Several interviewees reported that they had to 'adapt' the guidance laid out in the manuals in order to complete a task efficiently within a defined timescale. In addition to this interviewees also reported delays in accessing the required parts for maintenance tasks. This was balanced against external pressure to produce a flight worthy aircraft, within a strict schedule, which could require the modification of recommended procedures (Bamber, Gittell, Kochan \& Nordenflycht, 2009). Such actions have been classified as 'routine violations' (Lawton, 1998), and have been linked to incidents that adversely impact maintenance work quality (Hobbs \& Williamson, 2002). 


\section{Lone-worker non-technical skills}

A lone worker is an individual who works alone, separate from a team and without direct supervision, on a regular or occasional basis (NHS, 2005). In the current study lone workers were those who worked at a separate location or out of sight of the rest of their team.

Research suggests that lone working is associated with several risks, including the prospect of accident or injury (Huang et al., 2013). As such it is important that lone workers prioritise safety, and that managers or supervisors support safety behaviours and protocol compliance (Lee et al., 2014). Previous research based in agriculture identified the potential importance of NTS as a mechanism for ensuring safety in lone workers (Irwin \& Poots, 2015). The current interview findings replicate that result, and extend the importance of lone-worker NTS into the aircraft maintenance domain. This suggests that future research should consider the application of NTS to lone workers in other high-risk areas where workers might complete some task elements alone, as well as extending this research into spheres where workers are commonly alone.

\section{Conclusion}

The results indicate that non-technical skills are an important aspect of aircraft maintenance workers' work performance and safety, mirroring the findings reported within other high-risk industries. The application of NTS may vary across organizational units, this highlights the need for a behavioural marker in this field in order to provide a baseline assessment for maintenance teams. Such assessment would allow the production of a tailored training program, suited to addressing the needs of each team. The current findings represent the basis of a taxonomy for the development of a NTS Behavioural Marker system for utlilzation within the aircraft maintenance industry.

\section{Acknowledgements}


The authors would like to thank all of the aircraft maintenance participants for giving up their time to take part in this study. This research did not receive any specific grant from funding agencies in the public, commercial, or not-for-profit sectors.

\section{References}

Air Accident Investigation Branch (AAIB). (1996). Report on Boeing 737-400,G-OBMM, Near Daventry, on 23 February 1995. HMSO, London.

Atak, A. \& Kingma, S. (2011). Safety culture in an aircraft maintenance organisation: A view from the inside. Safety Science, 49, 268-278.

Baker, D. P., Krokos, K. J., \& Amodeo, A. M. (2008). TeamSTEPPS® Teamwork Attitudes Questionnaire.

Bamber, G., Gittell, J., Kochan, T. \& Nordenflycht, A. (2009). Up in the air: How airlines can improve performance by engaging their employees. Cornell University ILR Press, Ithaca, NY.

Braun, V. \& Clarke, V. (2006). Using thematic analysis in psychology. Qualitative Research in Psychology, 3, 77-101.

Butterfield, L.D., Borgen, W.A., Amundson, N.E. \& Maglio, A.T. (2005). Fifty years of the critical incident technique: 1954-2004 and beyond. Qualitative Research, 5, 475-497.

Civil Aviation Authority (CAA). (2003). Aviation maintenance human factors (EASA / JAR145 approved organisations). CAA, London.

CAA. (2002). Human factors in aircraft maintenance and inspection. CAA, London.

Chang, Y. \& Wang, Y. (2010). Significant human risk factors in aircraft maintenance technicians. Safety Science, 48, 54-62.

Comrey, A. L. \& Lee, H. B. (1992). A First Course in Factor Analysis. Hillsdale, NJ, Erlbaum. 
Darbra, R. M., Crawford, J. F. E., Haley, C. W., \& Morrison, R. J. (2007). Safety culture and hazard risk perception of Australian and New Zealand maritime pilots. Marine Policy, 31, 736-745.

Dupont, G. (1997). The dirty dozen in maintenance. In Meeting Proceedings Eleventh Federal Aviation Administration Meeting on Human Factors Issues in Aircraft Maintenance and Inspection: Human error in aviation maintenance. 45-49, Washington DC.

Endsley, M.R. (2015). Situation awareness: Misconceptions and misunderstandings. Journal of Cognitive Engineering and Decision-Making, 9, 4-32.

Endsley, M.R. \& Robertson, M.M. (2000). Situation awareness in aircraft maintenance teams. International Journal of Industrial Ergonomics, 26, 301-325.

Flanagan, J.C. (1954). The critical incident technique. Psychological Bulletin, 51, 327-358.

Fletcher, G., Flin, R., McGeorge, P., Glavin, R., Maran, N. \& Patey, R. (2004). Rating nontechnical skills: developing a behavioural marker system for use in anaesthesia. Cognition, Technology and Work, 6, 165-171.

Flin, R., Martin, L., Goeters, K., Hormann, H., Amalberti, R., Valot, C. \& Nijhuis,H. (2003). Development of the NOTECHS (non-technical skills) system for assessing pilots' CRM skills. Human Factors and Aerospace Safety, 3, 95-117.

Flin, R., O’Connor, P. \& Crichton, M. (2008). Safety at the Sharp End: A Guide to NonTechnical Skills. Ashgate, Farnham.

Flin, R., \& Patey, R. (2009). Improving patient safety through training in non-technical skills. BMJ, b3595.

Francis, J.J., Johnstone, M., Robertson, C., Glidewell, L., Entwhitle, V., Eccles, M.P. \& Grimshaw, J.M. (2010). What is an adequate sample size? Operationalising data saturation for theory based interview studies. Psychology of Health, 25, 1229-1245. 
George, D., \& Mallery, P. (2003). SPSS for Windows step by step: A simple guide and reference. 11.0 update (4th ed.). Boston: Allyn \& Bacon.

Graeber, R.C. \& Marx, D.A. (1993). Reducing human error in aircraft maintenance operations. Proceedings of the Flight Safety Foundation $46^{\text {th }}$ Annual Air Safety Seminar, Kuala Lumpar, Malaysia.

Guest, G., Bunce, A. \& Johnson, L. (2006). How many interviews are enough? An experiment with data saturation and variability. Field Methods, 18, 59-82.

Hampson, I., Junor, A. \& Gregson, S. (2012). Missing in action: aircraft maintenance and the recent 'HRM in the airlines' literature. The International Journal of Human Resource Management, 23, 2561-2575.

Heinemann, G. D., Schmitt, M. H., Farrell, M. P., \& Brallier, S. A. (1999). Development of an attitudes toward health care teams scale. Evaluation \& the Health Professions, 22, 123 142.

Helmreich, R. L., Merritt, A. C., \& Wilhelm, J. A. (1999). The evolution of crew resource management training in commercial aviation. The International Journal of Aviation Psychology, 9, 19-32.

Hobbs, A. \& Williamson, A. (2002). Unsafe acts and unsafe outcomes in aircraft maintenance. Ergonomics, 10, 866-882.

Hobbs, A. (2008). An overview of human factors in aviation maintenance. Australian Safety Transport Bureau, Australia.

Huang, Y., Zohar, D. Robertson, M.M., Garabet, A., Lee, J. \& Murphy, L.A. (2013). Development and validation of safety climate scales for lone workers using truck drivers as an exemplar. Transportation Research Part F: Traffic Psychology and Behaviour, 17, 5-19. 
Irwin, A. \& Poots, J. (2015). The human factor in agriculture: an interview study to identify farmers' non-technical skills. Safety Science, 74, 114-121.

Kraus, D.C. \& Gramopadhye, A.K. (2001). Effect of team training on aircraft maintenance technicians: computer based training versus instructor based training. International Journal of Industrial Ergonomics, 27, 141-157.

Lawton, R. (1998). Not working to rule: understanding procedural violations at work. Safety Science, 28, 77-95.

Lee, J., Huang, Y., Robertson, M.M., Murphy, L.A., Garabet, A. \& Chang, W. (2014). External validity of a generic safety climate scale for lone workers across different industries and companies. Accident Analysis and Prevention, 63, 138-145.

Marx, D.A. \& Graeber, R.C. (1993). Human Error in Aircraft Maintenance. Boeing Commercial Airplane Group. Seattle, Washington.

Mitchell, L., Flin, R., Yule, S., Mitchell, J., Coutts, K. \& Youngson, G. (2011). Thinking ahead of the surgeon. An interview study to identify scrub nurses' non-technical skills. International Journal of Nursing Studies, 48, 818-828.

National Health Service (NHS) (2005). Not alone: A guidance for lone workers. http://www.nhsbsa.nhs.uk/SecurityManagement/Documents/Lone_Working_Guidance_fin al.pdf. Retrieved $11^{\text {th }}$ December, 2014.

Neale, G. Woloshynowych, M. \& Vincent, C. (2001). Exploring the causes of adverse events in NHS hospital practice. Journal of the Royal Society of Medicine, 94, 322-330.

Rammstedt, B., Danner, D. \& Bosnjak, M. (2017). Acquiescence response styles: A multilevel model explaining individual-level and country-level differences. Personality and Individual Differences, 1, 190-194.

Sexton, J. B., Thomas, E. J., \& Helmreich, R. L. (2000). Error, stress, and teamwork in medicine and aviation: cross sectional surveys. BMJ, 320, 745-749. 
Shappell, S., Detwiler, C., Holcomb, K., Hackworth, C., Boquet, A., \& Wiegmann, D. A. (2007). Human error and commercial aviation accidents: an analysis using the human factors analysis and classification system. Human Factors, 49, 227-242.

Singer, S., Lin, S., Falwell, A., Gaba, D., \& Baker, L. (2009). Relationship of safety climate and safety performance in hospitals. Health Services Research, 44, 399-421.

Sneddon, A., Mearns, K. \& Flin, R. (2006). Safety and situation awareness in offshore crews. Cognition, Technology and Work, 8, 255-267.

Sternberg, R.J. \& Horvath, J.A. (1999). Tacit Knowledge in Professional Practice: Researcher and Practitioner Perspectives. Laurence Erlbaum Associates, Mahwah, New Jersey.

Suzuki, T., von Thaden, T.L. \& Geibel, W.D. (2008). Coordination and safety behaviours in commercial aircraft maintenance. Proceedings of the Human Factors and Ergonomics Society $52^{\text {nd }}$ Annual Meeting, 89-93.

Taylor, J.C. \& Thomas, R.L. (2003). Toward measuring safety culture in aviation maintenance: The structure of trust and professionalism. The International Journal of Aviation Psychology, 13, 321-43.

Wang, T. \& Chuang, L. (2014). Psychological and physiological fatigue variation and fatigue factors in aircraft line maintenance crews. International Journal of Industrial Ergonomics, $44,107-113$

Yule, S., Flin, R., Paterson-Brown, R. \& Maran, N. (2006). Development of a rating system for surgeons non-technical skills. Medical Education, 40, 1098-1105. 